\title{
Characterization, Virulence, Epidemiology, and Management of Anthracnose in Celery
}

Lina M. Rodriguez-Salamanca, Former Graduate Research Assistant, Department of Plant, Soil, and Microbial Sciences, Michigan State University, East Lansing 48824; Lina M. Quesada-Ocampo, Assistant Professor, Department of Plant Pathology, Raleigh North Carolina State University; Rachel P. Naegele, Visiting Research Associate and Mary K. Hausbeck, Professor, Department of Plant, Soil, and Microbial Sciences, Michigan State University

\begin{abstract}
Rodriguez-Salamanca, L. M., Quesada-Ocampo, L. M., Naegele, R. P., and Hausbeck, M. K. 2015. Characterization, virulence, epidemiology, and management of leaf curling and petiole anthracnose in celery. Plant Dis. 99:1832-1840.

Leaf curling and petiole twisting of celery (Apium graveolens) were observed in several commercial fields in five Michigan counties in 2010 through 2012, causing significant crop damage and loss. Prior to this time, the pathogen Colletotrichum acutatum species complex had not been previously associated with celery in Michigan. In this study, the pathogen's genotype and phenotype were characterized, the influence of environmental conditions determined, and fungicides tested. Pathogen identification was based on conidial morphology and molecular identification using species-specific primers. Intersimple-sequence repeat (ISSR) banding patterns were similar between $C$. acutatum isolates from celery $(n=51)$ and blueberry $(n=1)$ but different from $C$. dematium and C. gloeosporioides. Four ISSR primers resulted in $4 \%$ polymorphism when

tested on isolates from celery. Pathogenicity and virulence of $C$. acutatum sensu lato isolated from celery $(n=81)$, tomato $(n=2)$, and blueberry $(n=1)$ were evaluated in greenhouse experiments, which revealed differences in virulence among isolates but no significant differences specific to collection year, county, or field. In dew chambers and growth chambers, high temperatures $\left(\geq 25^{\circ} \mathrm{C}\right)$ or long leaf wetness duration $(>24 \mathrm{~h})$ increased disease incidence. Twelve fungicides were tested in field studies over two growing seasons to determine their efficacy against celery anthracnose. The fungicides azoxystrobin, pyraclostrobin, mancozeb, and chlorothalonil reduced disease by 27 to $50 \%$ compared with the untreated control when disease pressure was moderate.
\end{abstract}

In the United States, 11,900 ha of celery (Apium graveolens L. var. dulce (Mill.) Pers.) were planted in 2013 and, in total, 52,580 tons were harvested, valued at approximately \$20 million (Anonymous 2013). Celery is grown in organic soils on the west side of Michigan's lower peninsula, cultivated for both the fresh and processing markets. In 2010, inward curling of the leaves and inconspicuous elliptical sunken lesions along the petioles were observed and determined to be caused by Colletotrichum acutatum sensu lato (s.l.), which causes celery leaf curl and petiole anthracnose (Rodríguez-Salamanca et al. 2012). Symptoms of the disease include parallel lesions along the petioles that are light brown to brown in color. Leaf curling and petiole twisting can be observed on seedlings and older celery plants. The celery heart (younger tissue in the center of the plant) is sometimes discolored in affected plants; this symptom is often observed in plants with curled leaves and discolored margins. C. acutatum on celery is a new disease pathogen to the United States and information about pathogen biology, epidemiology, population structure, and management strategies is limited (Rodríguez-Salamanca et al. 2012).

Multiple studies have characterized $C$. acutatum s.l. isolates in other host species based on conidial and appresorial morphology, epidemiology, and molecular marker variation (Freeman et al. 2001b; Johnston and Jones 1997; Lardner et al. 1999; Sreenivasaprasad and Talhinhas 2005). The epidemiology of $C$. acutatum has been extensively studied in strawberry (King et al. 1997; Leandro et al. 2003; Madden and Boudreau 1997; Madden et al. 1993; Ntahimpera et al. 1997; Wilson et al. 1990) and, more recently, in almond (Dieguez-Uribeondo et al. 2011) and olive (Moral et al. 2012). In

\section{Corresponding author: M. K. Hausbeck; E-mail: hausbec1@msu.edu}

*The $\boldsymbol{e}$-Xtra logo stands for "electronic extra" and indicates that two supplementary tables are included in the online edition.

Accepted for publication 11 February 2015.

http://dx.doi.org/10.1094/PDIS-09-14-0994-RE

(c) 2015 The American Phytopathological Society general, disease incidence increased with leaf wetness duration in strawberry fruit (Wilson et al. 1990) and almond blossoms and leaves (Dieguez-Uribeondo et al. 2011). Optimal infection temperatures changed depending upon the host: 25 to $30^{\circ} \mathrm{C}$ in strawberry (Wilson et al. 1990), 15 to $20^{\circ} \mathrm{C}$ in almond (Dieguez-Uribeondo et al. 2011), and 17 to $24^{\circ} \mathrm{C}$ in olive (Moral et al. 2012). In strawberry, infection models and disease thresholds have incorporated environmental conditions to forecast fruit infection and schedule fungicide applications (MacKenzie and Peres 2012). Environmental conditions conducive to celery anthracnose disease progression are currently unknown. Knowledge of optimal conditions for disease, combined with information on fungicide sensitivity and genotypic diversity, are important for developing effective and durable management strategies.

In Michigan, effective fungicides are needed to manage this new disease of celery. Traditional fungicides, including active ingredients such as copper, thiram, mancozeb, and chlorothalonil, have been used to limit celery leaf curl under glasshouse and field conditions in Australia (Heaton and Dullahide 1993) but fungicides have not been tested for celery anthracnose in the United States. New fungicides are now available to limit diseases caused by Colletotrichum spp. on various crops, including the quinone inhibitors or strobilurins (MacKenzie and Peres 2012), and demethylation inhibitors (Freeman et al. 1997). Multisite protectant fungicides such as chlorothalonil and mancozeb have historically been included in spray programs to manage diseases caused by Colletotrichum spp. in celery and other crops (Adaskaveg and Forster 2000; Freeman 2008; Freeman et al. 1997; Chapin et al. 2006; Jeffries et al. 1990). However, the efficacy of fungicides to manage celery anthracnose under Michigan's environmental conditions has not been tested.

Accurate diagnostics and proper identification of the pathogen species causing the disease is essential for disease management. Species-specific diagnostic markers have been widely used to differentiate among C. acutatum, C. gloeosporioides, and other Colletotrichum spp. (Silva-Rojas and Ávila-Quezada 2011). Techniques that use arbitrary random molecular markers such as intersimplesequence repeat (ISSR) (Mishra et al. 2003; Rampersad 2013), randomly amplified polymorphic DNA (Whitelaw-Weckert et al. 2007) and restriction fragment length polymorphism (Guerber 
et al. 2003) have been employed to study genotypic diversity in pathogen populations. Nonetheless, the genetic diversity of $C$. acutatum s.l. isolated from celery in Michigan is currently unknown.

To address some of the knowledge gaps needed to effectively manage celery anthracnose in Michigan and other regions of the United States, we sought to (i) investigate the pathogenicity, virulence, and genetic variability within $C$. acutatum s.l. isolated from celery; (ii) determine the effects of temperature and leaf wetness duration on C. acutatum s.l. infection and disease progression on celery petioles and leaves; and (iii) evaluate fungicides for their ability to limit celery leaf curl and petiole anthracnose in the field.

\section{Materials and Methods}

Isolate collection and maintenance. From 2010 through 2012, 58 fields (29, 14, and 5 fields sampled in 2010, 2011, and 2012, respectively) across five counties in Michigan were scouted for leaf curling and lesions on the petioles (Supplementary Table S1). In each field, symptomatic celery petioles were collected and transported to the lab, where the pathogen was isolated onto $25 \%$ strength potato dextrose agar (PDA). A C. acutatum isolate from blueberry (used as a positive control), single isolates of $C$. dematium and $C$. gloeosporioides (used as negative controls) (all courtesy of A. Schilder, Michigan State University), and two Colletotrichum spp. isolated from tomato in Michigan (both collected in 2011), were included in the culture collection.

Monosporic cultures of all isolates were maintained in long-term storage as mycelial plugs in $700 \mu \mathrm{l}$ of $30 \%$ glycerol at $-20^{\circ} \mathrm{C}$, and as $200 \mu \mathrm{l}$ of conidial suspension mixed with $1,000 \mu \mathrm{l}$ of conservation media ( $20 \%$ glycerol, $0.04 \%$ yeast extract, $0.1 \%$ malt extract, $0.04 \%$ glucose, and $0.02 \% \mathrm{~K}_{2} \mathrm{HPO}_{4}$ ) at $-80^{\circ} \mathrm{C}$ in $2.0-\mathrm{ml}$ cryogenic vials (Sigma-Aldrich, St. Louis); both techniques were modified from Dhingra and Sinclair (1985). For subsequent experiments, isolates were transferred onto $50 \%$ strength PDA from long-term storage and incubated for 7 days under fluorescent light at $21 \pm 2{ }^{\circ} \mathrm{C}$.

Isolate genotyping. For DNA extractions, Colletotrichum spp. were grown in $35 \mathrm{ml}$ of $50 \%$ strength potato dextrose broth and incubated on a rotary shaker for 7 days at $21 \pm 2{ }^{\circ} \mathrm{C}$. Mycelial masses were vacuum filtered and lyophilized overnight on a FreeZone 1-liter Benchtop Freeze Dry System (Labconco, Kansas City, MO). Dry mycelium was macerated and $500 \mu l$ of extraction buffer (AutoGen, Inc., Holliston, MA) was added. The samples were submitted to the Michigan State University (MSU) Research Technology Support Facility (East Lansing) for robotically assisted DNA extraction using AutoGen 740 (AutoGen Inc.). DNA quality and integrity was analyzed by electrophoresis in $1 \%$ (wt/vol) agarose gel in $0.5 \times$ Trisborate-EDTA buffer (Maniatis et al. 1982) and stained with ethidium bromide $(5 \mu \mathrm{g} / \mathrm{ml})$ for visualization (Maniatis et al. 1982). DNA concentration was quantified using a NanoDrop ND 1000 spectrophotometer (Thermo Scientific, Wilmington, DE) and the NanoDrop $2.4 .7 \mathrm{c}$ software and diluted to $10 \mathrm{ng} / \mu \mathrm{l}$ for polymerase chain reaction (PCR) amplification.

The $C$. acutatum-specific primers CaInt2 and internal transcribed spacer (ITS) 4 were used to amplify DNA from 113 C. acutatum s.l. isolates, as described (Mills et al. 1992), but using an annealing temperature of $60^{\circ} \mathrm{C}$. The 490 -bp PCR fragment was visualized in a $2 \%$ agarose gel, stained with ethidium bromide, and compared with a 100-bp DNA ladder (New England Biolabs Inc., Ipswich, MA). In addition, a panel of six isolates, including one isolate recovered from celery in 2010 and 2011, an isolate from tomato, and positive (C. acutatum from blueberry) and negative controls ( $C$. dematium and $C$. gloeosporioides), were used to evaluate five ISSR motifs (GTC5, CAG5, GACAC3, GACA4, and TCC5) for polymorphism. Four ISSR motifs with confirmed polymorphism were amplified on a larger panel of isolates $(n=56)$, including $C$. acutatum s.l. isolated from celery $(n=51)$, tomato $(n=2)$, and control isolates $(n=3)$. PCR was performed in a $20-\mu \mathrm{l}$ final volume containing $50 \mathrm{ng}$ of genomic DNA, $1 \mathrm{mM}$ primer, $1 \times$ PCR buffer (Promega Corp., Madison, WI), $250 \mathrm{mM}$ total dNTPs, and $1.25 \mathrm{U}$ of Go Taq polymerase (Promega Corp.). Markers were amplified in an Eppendorf Mastercycler ep systems thermal cycler (Eppendorf, Westbury, NY) using the following program: hot start of $95^{\circ} \mathrm{C}$ for $1 \mathrm{~min} ; 30$ cycles of $95^{\circ} \mathrm{C}$ denaturing for $30 \mathrm{~s}$ and $48^{\circ} \mathrm{C}$ (GACAC3, GACA4 and TCC5) or $60^{\circ} \mathrm{C}$ (CGA5 and GTG5) annealing for $30 \mathrm{~s}$; and a $72^{\circ} \mathrm{C}$ extension for 1.5 min. PCR fragments were separated on $2 \%$ agarose gels stained with ethidium bromide and compared with a 100-bp or 1-kb DNA ladder (New England Biolabs Inc.).

Pathogenicity and virulence experiments. Individual cultures of 85 C. acutatum s.l. isolates, which included a subset of isolates used in genotyping experiments, were flooded with $3 \mathrm{ml}$ of doubledistilled (dd) $\mathrm{H}_{2} \mathrm{O}$, and conidia were dislodged with a sterile glass cell spreader. The suspension was collected from each plate and added to $17 \mathrm{ml}$ of $0.001 \%$ Tween $\mathrm{ddH}_{2} \mathrm{O}$ and a hemacytometer was used to determine conidial concentration; the conidial suspension was adjusted to $1.0 \times 10^{6}$ conidia/ml using sterile $\mathrm{ddH}_{2} \mathrm{O}$ with $0.001 \%$ Tween.

Humid chambers (178 by 100 by $63 \mathrm{~cm}$ [length by width by height]) consisting of a balsa wood frame wrapped in clear plastic were placed on a greenhouse bench. The inside of the chambers was sprayed with distilled water; damp paper towels were placed on the border and across the center of the chambers to ensure high $(95 \pm 5 \%)$ relative humidity $(\mathrm{RH})$. A Watchdog (Spectrum Technologies Inc., Plainfield, IL) was placed inside each humid chamber to measure temperature and RH. Four-week-old 'Green Bay' celery seedlings were placed in the humid chambers overnight prior to inoculation. Seedlings were spray inoculated with $1 \mathrm{ml}$ of conidial suspension and returned to the chambers. A randomized complete block design, with one celery seedling per isolate per humid chamber, was used with three replicate humid chambers. Celery plants were rated 5,7,14, and 21 days after inoculation (DAI). The number of lesions on the petioles was used to calculate the lesion area under the disease progress curve (LAUDPC). To confirm that symptoms were caused by $C$. acutatum, the pathogen was reisolated from $40 \%$ of the inoculated plants. The experiment was repeated two times.

Morphological characterization. Microscopic characteristics were examined for 62 Colletotrichum spp. isolated from celery in Michigan, which included a subset of $C$. acutatum s.l. isolates used in genotyping and virulence experiments. Monosporic isolates were grown in $25 \%$ strength PDA and incubated at $21 \pm 2{ }^{\circ} \mathrm{C}$ under fluorescent light for 7 days. Conidial masses were then scraped from the colonies with a sterile toothpick, mounted onto a glass slide with $15 \mu \mathrm{l}$ of lactophenol solution $(10 \mathrm{ml}$ of phenol, $10 \mathrm{ml}$ of lactic acid, $10 \mathrm{ml}$ of glacial acetic acid, and $10 \mathrm{ml}$ of $\mathrm{H}_{2} \mathrm{O}$ ), and sealed with Cytoseal 60 (Thermo Scientific, Waltham, MA). Permanent slides were then inspected under a light microscope (Leica Microsystems, Wetzlar, Germany) and photographs were taken with a Leica Digital camera DC 300 (Leica Microsystems) at $\times 400$ magnification. For each isolate, conidial length and width of 10 randomly chosen conidia were measured. The experiment was conducted twice.

Temperature and leaf wetness experiments. The effect of temperature and leaf wetness duration on disease progression was tested on 6-week-old Green Bay celery seedlings. Celery seedlings were moved from a greenhouse and placed in a dew chamber (Model I35-DL; Percival Scientific Inc., Boone, IA) at $96 \pm 3 \%$ RH, $25 \pm$ $2{ }^{\circ} \mathrm{C}$ (day), and $20 \pm 2{ }^{\circ} \mathrm{C}$ (night) overnight for $19 \mathrm{~h}$. Inoculum was prepared as described for pathogenicity and virulence experiments using an equal mixture of five $C$. acutatum s.l. isolates from celery in Michigan in 2010: isolates C1213, C2612 (NRRL accession number 62812), C2713 (NRRL 62813), C40110 (NRRL 62814), and C4211 (NRRL 62815). Celery plants were retrieved from the dew chamber, and leaves and petioles were spray inoculated with $1 \mathrm{ml}$ of the $C$. acutatum conidial suspension $\left(1.0 \times 10^{6}\right.$ conidia $\left./ \mathrm{ml}\right)$. Plants were returned to the dew chamber immediately after inoculation. Plants assigned to $0 \mathrm{~h}$ of leaf wetness were randomly assigned to growth chambers (Model CMP3244; Conviron, Pembina, ND) set at $15,20,25$, or $30^{\circ} \mathrm{C}$. All other leaf wetness periods $(12,24$, 48,72 , and $96 \mathrm{~h}$ ) were completed in the dew chamber, and two plants from each wetness treatment were moved to the growth chambers at each of the four different temperatures. Noninoculated control plants were exposed for 0,48 , or $96 \mathrm{~h}$ of leaf wetness and incubated at each temperature treatment. 
Plants were evaluated weekly until 21 DAI. The number of lesions on the petioles and number of curled leaves were used to calculate the LAUDPC and leaf curl AUDPC (CAUDPC), respectively. The experiment was a split-plot design with two fixed factors. The three whole replications (in time) were treated as a blocking factor, temperature was treated as the whole-plot factor within each block (replication), and leaf wetness duration was treated as the subplot factor within each temperature. The pathogen was confirmed by isolations from $20 \%$ of the inoculated plants in each block.

Fungicide experiments. Field plots were located at the MSU Plant Pathology Farm, East Lansing, in a field of Houghton muck. Blocks 3 and 4 were pure Houghton muck while blocks 1 and 2 contained 13\% sandy loam (Anonymous 2012). The field was previously planted to tomato (2010) and pepper (2011). On 3 June 2011 and 23 May 2012, 5-week-old Green Bay celery seedlings were transplanted in the field $16 \mathrm{~cm}$ apart in rows that were $0.9 \mathrm{~m}$ apart. The treatment plots were $6.1 \mathrm{~m}$ long, with a buffer row in between fungicide treatment plots and $0.7 \mathrm{~m}$ between blocks. Treatments applied to Green Bay celery in 2011 included azoxystrobin (Quadris 2.08SC, $0.22 \mathrm{~kg}$ active ingredient [a.i.]/ha; Syngenta Crop Protection, Inc., Greensboro, NC; FRAC group 11), chlorothalonil (Bravo WeatherStik 6SC, $1.68 \mathrm{~kg}$ a.i./ha; Syngenta Crop Protection, Inc.; FRAC M5), the same rate of chlorothalonil tank mixed with cuprous oxide (Nordox 75WG, $1.05 \mathrm{~kg}$ a.i./ha; DuPont de Nemours and Co., Wilmington, DE; FRAC M1), copper hydroxide (Kocide 3000 51DF, $0.8613 \mathrm{~kg}$ a.i./ha; DuPont de Nemours and Co.), difenoconazole (Inspire 5SC, $0.13 \mathrm{~kg}$ a.i./ha; Syngenta Crop Protection, Inc.; FRAC 3), fluopyram/pyrimethanil (Luna Tranquility 4.17SC, $0.58 \mathrm{~kg}$ a.i./ha; Bayer CropScience LP, Research Triangle Park, NC; FRAC 7/9), propiconazole (Tilt 2.08EC, $0.23 \mathrm{~kg}$ a.i./ha; Syngenta Crop Protection, Inc.; FRAC 3), pyraclostrobin (Cabrio 3.3EC, $0.17 \mathrm{~kg}$ a.i./ha; BASF Corp., Research Triangle Park, NC; FRAC 11), pyrimethanil (Scala 20WG, $0.79 \mathrm{~kg}$ a.i./ha; Bayer CropScience LP; FRAC 9), mancozeb (Manzate ProStik 75DF, $2.52 \mathrm{~kg}$ a.i./ha; DuPont de Nemours and Co.; FRAC M3), and an untreated inoculated control. Treatments were repeated in 2012, with the addition of boscalid (Endura 70WG, $0.36 \mathrm{~kg}$ a.i./ha; BASF Corp.; FRAC 7), fluxapyroxad/pyraclostrobin (Priaxor 4.17SC, $0.22 \mathrm{~kg}$ a.i./ha; BASF Corp.; FRAC 7/11), and an untreated noninoculated control. The designated fungicide treatments were applied once or twice to the plots prior to inoculation with $C$. acutatum. Postinoculation (described below), fungicides were applied at a 7- to 10-day interval, depending on the weather. In total, 10,7 , and 6 fungicide applications were made for the 2011-A, 2011-B, and 2012-C trials, respectively. The late inoculation of trial 2011-B occurred after the precipitation in late July but these relatively large celery plants received the same amount of inoculum that smaller plants received in trials 2011-A and 2012-C.

A mist irrigation system was used to maintain water requirements of the crop and promote $C$. acutatum infection, dispersal, and disease development throughout the experiment. Prior to inoculation, the mist irrigation system was operated for $2 \mathrm{~h}$ to provide leaf wetness and high RH conducive to infection in the field. The misting system was operated for 2 or $4 \mathrm{~h}$ every other day, depending on forecasted and actual precipitation. Sporulating cultures of C. acutatum s.l. (7-day-old cultures of isolates C1213, C2612, C2713, C40110, and
C4211; 12 plates per isolate) were placed in a blender with $300 \mathrm{ml}$ of $0.001 \%$ Tween $\mathrm{ddH}_{2} \mathrm{O}$ and blended to dislodge conidia. The resulting mixture of isolates was strained through four layers of sterile cheesecloth and the conidial concentration was adjusted to $1.0 \times$ $10^{6}$ conidia/ml. Plants within plots were inoculated at dusk with a hand-pump sprayer equipped with one hollow-cone nozzle that delivered approximately 168 liter/ha. Incidence and severity of celery leaf curl and petiole anthracnose was evaluated weekly from 5 to $53 \mathrm{DAI}$ on plants in the inner $5.5 \mathrm{~m}$ of each treatment plot. Severity was visually assessed using a 0 -to- 5 scale, as follows: $0=$ no symptoms, $1=>1$ to $10 \%, 2=>10$ to $25 \%, 3=>25$ to $50 \%, 4=>50$ to $75 \%$, and $5=>75$ to $100 \%$ of plant area showing leaf curl and petiole anthracnose symptoms. At the end of the field experiment, plots were hand harvested. Healthy plants were trimmed following fresh-market specifications (Bounds and Hausbeck 2007), and weighed for marketable yield. The diseased tissue was considered to be trimmings or nonmarketable weight. The pathogen was confirmed by reisolating from four plants in all plots per block.

Statistical analysis. LAUDPC, CAUDPC, incidence, severity, and yield (field trial only) were analyzed using the PROC MIXED and PROC GLIMMIX procedure of the SAS statistical analysis software (v9.2; SAS Institute Inc., Cary NC). Data were tested for equal variances using Levene's test. Residual normal distribution was tested using box plots, normality plots, q-q plots, and the ShapiroWilk test. Analysis of variance was evaluated using type III test results to determine significance of experimental factors. Significant differences $(\alpha=0.05)$ were separated by least square difference tests. Disease severity AUDPC (SAUDPC) data were calculated from an ordinal rating scale and analyzed using a nonparametric analysis, as described by Shah and Madden (2004), to determine the effect of weekly fungicides sprays on celery anthracnose progression in the field. A significance level of $P=0.05$ was used for all pairwise comparisons.

\section{Results}

Isolate collection and morphological characterization. In total, 87,100 , and $40 \%$ of the fields scouted had plants with symptoms of celery anthracnose in 2010, 2011, and 2012, respectively, indicating that this disease was widespread across Michigan celery-producing counties (Allegan, Barry, Kent, Ottawa, and Van Buren). Only 8 fields of the 58 scouted appeared to be free of celery anthracnose. In total, 180, 325, and 44 isolates were collected in 2010, 2011, and 2012, respectively. A subset of 62 Colletotrichum spp. isolates evaluated for microscopic characteristics had elliptical conidia with one (or both) acute ends and conidial sizes ranging from 7.1 to $12.1 \mu \mathrm{m}$ in length by 2.3 to $5.1 \mu \mathrm{m}$ in width (Table 1 ; Supplementary Table S2).

Isolate genotyping. From the 113 Colletotrichum spp. isolates included in genotyping with the species-specific CaInt2/ITS4 primer combination, 112 yielded the 490-bp fragment expected. This included 109 Colletotrichum spp. isolated from celery and C. acutatum isolates from blueberry and tomato (positive controls). The speciesspecific marker did not amplify isolate C578 from celery (this isolate was not confirmed to species), the negative controls ( $C$. dematium and $C$. gloeosporioides), or the blank reaction. Based on morphological

Table 1. Conidial size of Colletotrichum spp. isolated from celery with celery leaf and neck anthracnose symptoms ${ }^{\mathrm{z}}$

\begin{tabular}{|c|c|c|c|c|c|}
\hline \multirow[b]{2}{*}{ County $z$} & \multirow[b]{2}{*}{ Number of isolates } & \multicolumn{2}{|c|}{ Length $(\mu \mathrm{m})$} & \multicolumn{2}{|c|}{ Width $(\mu \mathrm{m})$} \\
\hline & & Mean & SE & Mean & SE \\
\hline Allegan & 5 & 9.52 & 0.25 & 3.14 & 0.06 \\
\hline Barry & 4 & 9.18 & 0.35 & 4.19 & 0.37 \\
\hline Kent & 21 & 9.85 & 0.10 & 3.24 & 0.02 \\
\hline NA & 6 & 8.74 & 0.20 & 3.04 & 0.06 \\
\hline Ottawa & 5 & 9.08 & 0.25 & 3.09 & 0.06 \\
\hline Van Buren & 21 & 9.61 & 0.11 & 3.13 & 0.03 \\
\hline Total isolates (grand mean) & 62 & 9.54 & 0.06 & 3.2 & 0.02 \\
\hline
\end{tabular}

${ }^{\mathrm{z}}$ Data grouped by county of collection; $\mathrm{SE}=$ standard error. 
characteristics and species-specific primers, 109 Colletotrichum spp. isolated from celery were identified as $C$. acutatum s.l.

From the initial ISSR survey, four primers yielded PCR products. Only the TCC5 primer did not amplify the $C$. acutatum DNA. On average, four loci were amplified, with a maximum of seven loci amplified with the CAG5 primer. When primers GTC5, CAG5, GACAC3, and GACA4 were tested on additional isolates, size and presence of bands were consistent with those observed in the initial survey. Isolate C578 showed differential patterns or did not amplify, depending on the primer set used, which provided additional evidence to designate this isolate as a different Colletotrichum sp. Polymorphism was low (4\%), with only two isolates (C53B2 and C24B113) showing differential banding patterns on two ISSR markers (Fig. 1). The majority $(96 \%)$ of isolates recovered from celery showed banding size
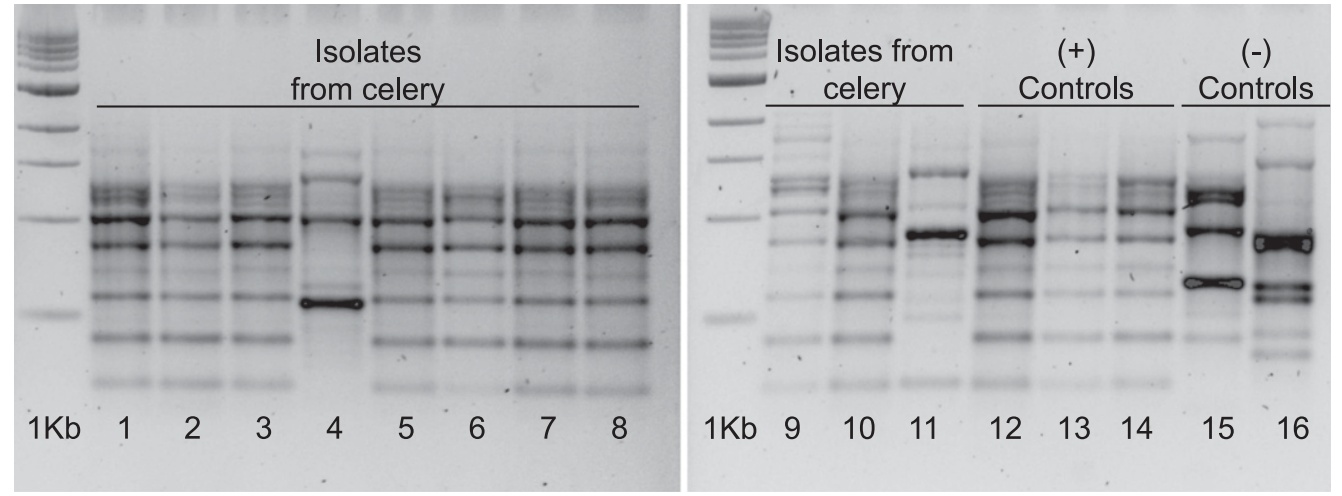

Fig. 1. Polymerase chain reaction amplification products obtained with intersimple-sequence repeat marker CAG5 amplified on DNA of Colletotrichum spp. isolates from celery: C5011 (lane 1), C5111 (lane 2), C53A5 (lane 3), C53B-2 (lane 4), C53C9 (lane 5), C53D2 (lane 6), C54S2 (lane 7), C54GB3 (lane 8), C54CRI1 (lane 9), C562 (lane 10), and C578 (lane 11); (+) control isolates: Tl-1 C.a (lane 12), T6 C.a (lane 13), and Cablu (lane 14); (-) control isolates: Cg104 (lane 15) and Cd 123 (lane 16).
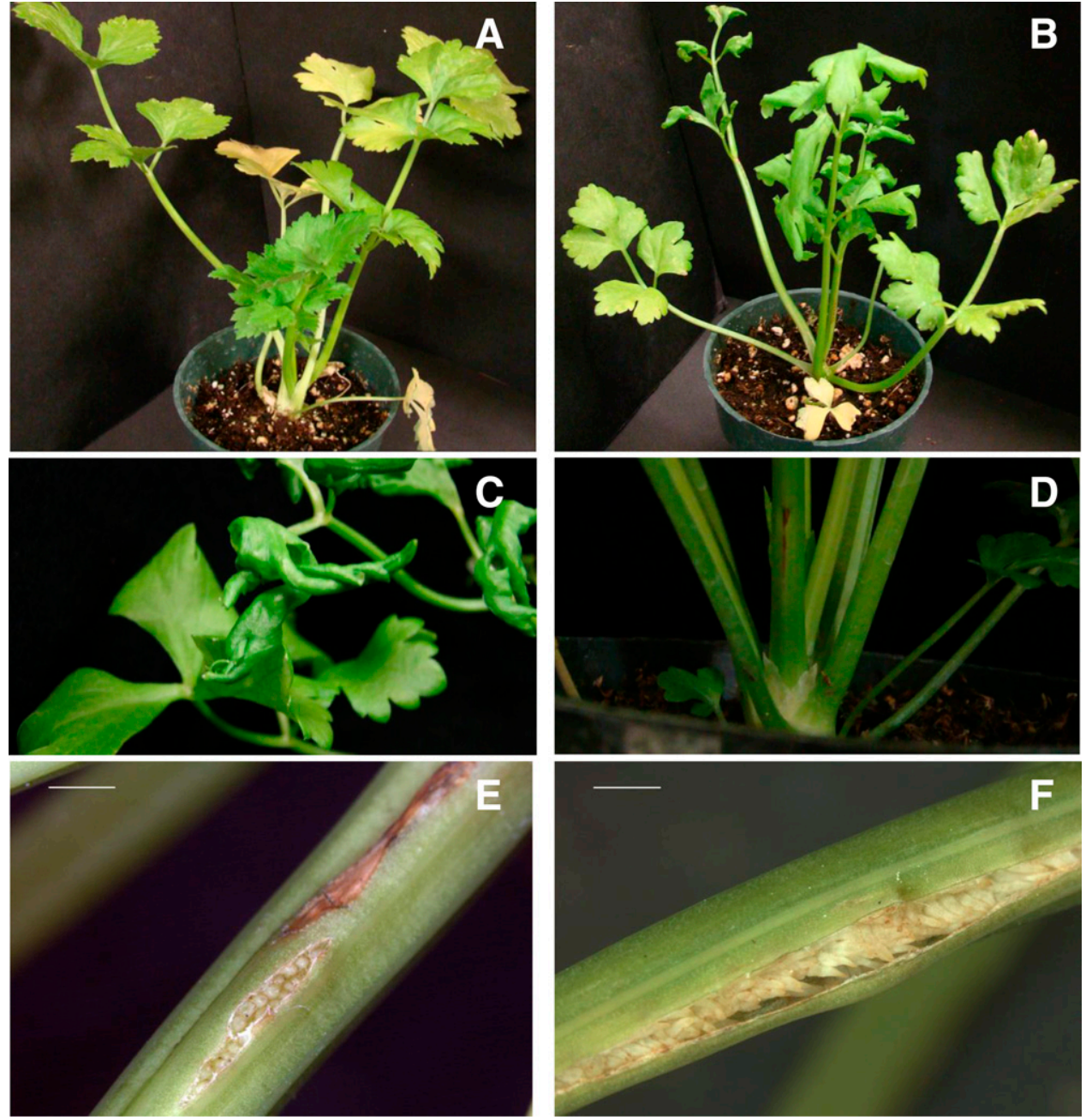

Fig. 2. 'Green Bay' celery, A, Control (noninoculated). B, Inoculated with Colletotrichum acutatum sensu lato. C, Leaf curl. D, Lesion on petiole. E, Lesion with plant tissue proliferation (gall) and $\mathbf{F}$, advanced tissue proliferation on lesion (adventitious roots). Scale bar $=3 \mathrm{~mm}$. 
and distribution patterns identical to the $C$. acutatum isolates from blueberry and tomato. Banding patterns were different from the negative controls included in the experiments $(C$. dematium and C. gloeosporioides).

Pathogenicity and virulence experiments. The $C$. acutatum s.l. isolates from celery $(n=81)$, blueberry $(n=1)$, and tomato $(n=2)$ were pathogenic to Green Bay celery seedlings. Isolate C578 (the Colletotrichum sp. isolate from celery that was not identified as C. acutatum s.l. with species-specific primers) failed to cause symptoms on celery seedlings. Leaf curling and lesions in petioles were the prevalent symptoms observed on celery plants infected with C. acutatum s.l. (Fig. 2B to D). Petiole twisting, adventitious root formation on lesions, or petiole galls (Fig. 2E and F) were observed at 14 to $21 \mathrm{DAI}$ but were not consistently observed for the same isolate or
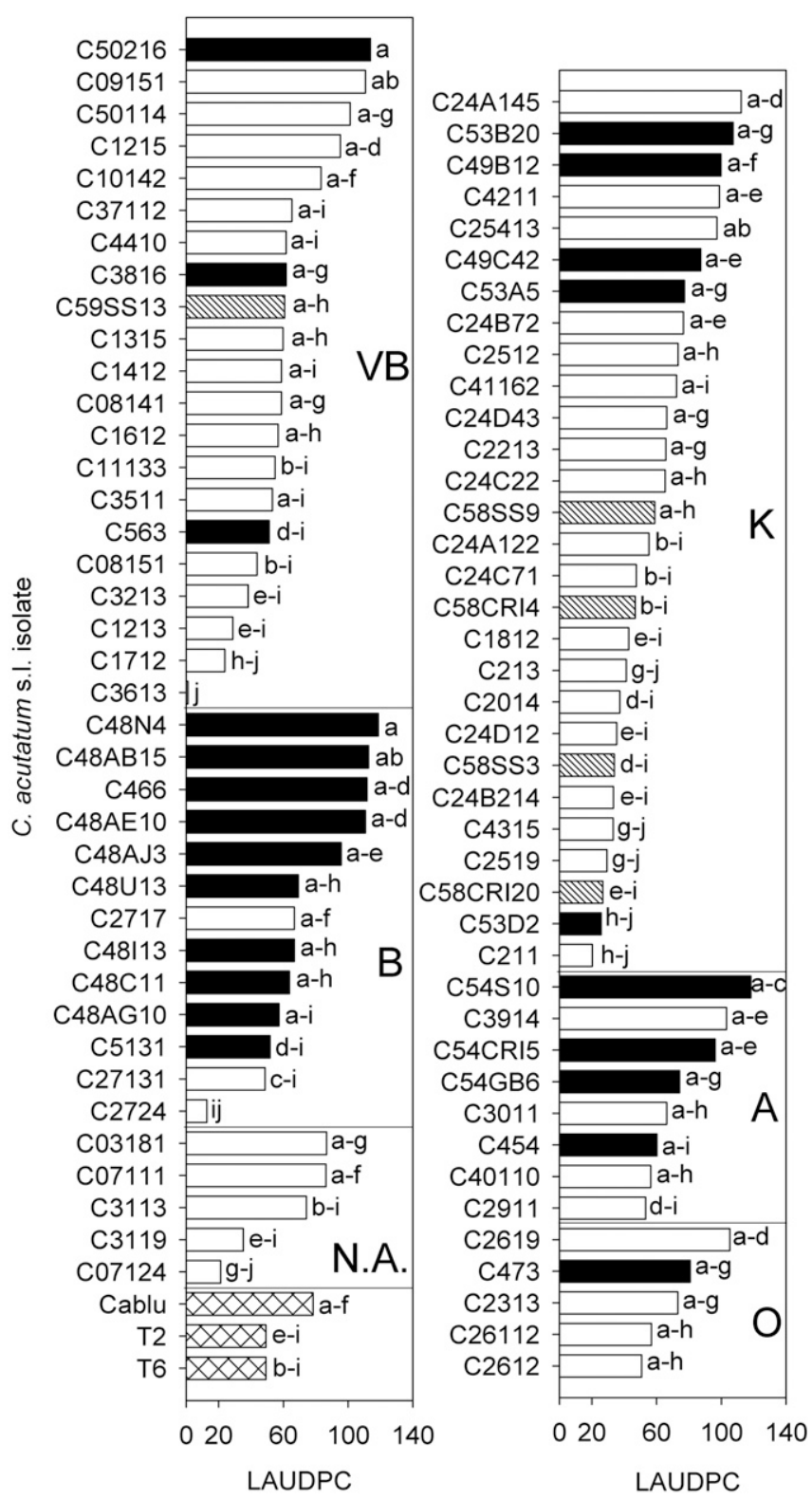

Fig. 3. Celery leaf curl and petiole anthracnose lesion area under the disease progress curve (LAUDPC) on 'Green Bay' celery seedlings inoculated with 1 of 84 Colletotrichum acutatum sensu lato isolates obtained from celery, tomato (T2 and T6), and blueberry (Cablu). Graphs group celery isolates by county where collected $(\mathrm{A}=$ Allegan, $\mathrm{B}=$ Barry, $\mathrm{K}=$ Kent, $\mathrm{O}=\mathrm{Ottawa}, \mathrm{VB}=$ Van Buren, and N.A. = no information available), collection year (open bars $=2010$, solid bars 2011, and hatched bars 2012), and isolates from other hosts (crosshatched bars). Bars with common letters are not significantly different according to least square difference $P=0.05$. at the same rating date across trials (data not shown). Lesion formation in petioles was observed across rating dates (7, 14, and $21 \mathrm{DAI})$. Occasionally, lesions on petioles coalesced and caused the petiole to break.

Experiment replications were analyzed together because no significant differences were found among them $(P=0.061)$. Differences in virulence among isolates were observed for disease incidence (Fig. 3). Isolates C50216 and C48N4 collected in Van Buren County and Barry County, respectively, during 2011 had the highest number of lesions over time, as reflected by LAUDPC values (Fig. 3). In contrast, isolate C3613 had the smallest LAUDPC value (Fig. 3). No trends in virulence were observed by year of collection or site of collection (i.e., county or field). The $C$. acutatum s.l. isolates were successfully reisolated from lesions on the petioles and discoloration on the margins of curled leaves (90 to $84 \%$ isolate recovery, respectively). Only 5 to $15 \%$ of the isolations from adventitious roots, galls, or twisted petioles without lesions yielded $C$. acutatum s.l.

Temperature and leaf wetness experiments. Celery seedlings inoculated with a $C$. acutatum s.l. mixture of isolates showed leaf curling and anthracnose petiole lesions 5 DAI. C. acutatum s.l. was able to infect petioles and cause symptoms in all combinations of leaf wetness duration and temperatures tested. Noninoculated controls remained disease free. Replications in time were analyzed as pooled data because no significant differences were found among whole-experiment replications $(P=0.099)$. A significant interaction between temperature and leaf wetness duration periods was not found for lesion count $(P=0.467)$ or for the number of curled leaves $(P=0.284)$. However, both temperature and leaf wetness duration had a significant effect on lesion numbers and number of curled leaves (Table 2).

The highest temperature $\left(30^{\circ} \mathrm{C}\right)$ or greatest duration of leaf wetness (96h) resulted in increased LAUDPC values, which were greater than any other temperature or leaf wetness duration tested (Table 2). LAUDPC values at $25^{\circ} \mathrm{C}$ were the second largest (Table 2), and significantly different from the smallest values observed at 15 and $20^{\circ} \mathrm{C}$. LAUDPC values of celery plants incubated at $48 \mathrm{~h}$ of wetness were intermediate, and similar to 72 and $24 \mathrm{~h}$ (Table 2). LAUDPC values were lowest at 0 or $12 \mathrm{~h}$ of leaf wetness.

A similar trend was observed in CAUDPC values for the hours of leaf wetness duration and the temperature level. At the greatest temperature or leaf wetness duration, CAUDPC values were greatest (Table 2). CAUDPC values at 25 and $30^{\circ} \mathrm{C}$ were similar, while the value at $20^{\circ} \mathrm{C}$ was not significantly different from CAUDPC values at 25 or $15^{\circ} \mathrm{C}$ (Table 2 ).

Table 2. Effect of temperature and leaf wetness duration on celery anthracnose incidence on 'Green Bay' celery seedlings inoculated with Colletotrichum acutatum sensu lato

\begin{tabular}{lcc}
\hline & \multicolumn{2}{c}{ Mean AUDPC $(\boldsymbol{P} \text { value })^{\mathbf{x}}$} \\
\cline { 2 - 3 } Factor & LAUDPC & CAUDPC \\
\hline Temperature $\left({ }^{\circ} \mathrm{C}\right)$ & $36.4 \mathrm{c}$ & \\
15 & $71.3 \mathrm{c}$ & $27.8 \mathrm{c}$ \\
20 & $100.0 \mathrm{~b}$ & $55.0 \mathrm{bc}$ \\
25 & $197.5 \mathrm{a}$ & $96.2 \mathrm{ab}$ \\
30 & & $120.5 \mathrm{a}$ \\
Leaf wetness duration $(\mathrm{h})$ & $20.0 \mathrm{~d}$ & \\
0 & $12.5 \mathrm{~d}$ & $41.5 \mathrm{~d}$ \\
12 & $58.1 \mathrm{c}$ & $30.3 \mathrm{~cd}$ \\
24 & $112.8 \mathrm{bc}$ & $62.6 \mathrm{cb}$ \\
48 & $139.3 \mathrm{~b}$ & $78.0 \mathrm{~b}$ \\
72 & $265.2 \mathrm{a}$ & $94.2 \mathrm{~b}$ \\
96 & $142.7 \mathrm{a}$ \\
\hline
\end{tabular}

${ }^{x}$ Mean area under the disease progress curve (AUDPC). Lesion AUDPC (LAUDPC): $P=0.023$ for temperature and $P<0.0001$ for leaf wetness. Leaf curl AUDPC (CAUDPC): $(P=0.0129)$ for temperature and $P<0.0001$ for leaf wetness. Values with common letters are not significantly different (least square difference $P=0.05$ ) within a factor and column. 
Fungicide experiments. The first celery anthracnose symptoms were observed in the untreated inoculated field plots 4 to 6 DAI. The initial symptoms included discoloration of the youngest tissue in the heart of the celery plants, followed by leaf cupping that was observed 7 to 14 DAI. Significant differences among treatments were found for anthracnose severity (mean rank SAUDPC) and final percentage of infected plants (Table 3 ). Trials were analyzed separately because significant differences were identified among trials. The untreated $C$. acutatum inoculated plots had between 96 to $100 \%$ infected plants at the end of the 2011 trials (Table 4). In 2012, 100\% of inoculated plants had a disease incidence of $100 \%$ at 5 DAI (data not shown). The 2012-C trial was harvested shortly after the untreated noninoculated plots began to show minor disease symptoms typical of $C$. acutatum s.l. infection (Table 4). It is likely that inoculum was splashed to the noninoculated control plots from nearby inoculated and diseased plots.

In the field trial 2011-A, the percent plants infected in the plots treated with mancozeb, chlorothalonil, pyraclostrobin, or azoxystrobin was significantly less compared with the untreated inoculated control or plots treated with fluopyram/pyrimethanil, pyrimethanil alone, difenoconazole, or copper hydroxide (Table 4). All treatments were effective at reducing anthracnose disease severity compared with the untreated inoculated control, with the exception of pyrimethanil and fluopyram/pyrimethanil (Table 4).

In the field trial 2011-B, mancozeb had the lowest celery anthracnose incidence, though it was not significantly different than pyraclostrobin, azoxystrobin, chlorothalonil, or cuprous oxide + chlorothalonil (Table 4). Plots treated with azoxystrobin, chlorothalonil, cuprous oxide + chlorothalonil, mancozeb, difenoconazole, propiconazole, and pyraclostrobin resulted in significantly smaller mean SAUDPC ranks compared with the untreated inoculated control (Table 4). In the 2012 field trial, pyraclostrobin was the only treatment with a significant difference in final anthracnose incidence from the untreated inoculated control (Table 4). Plots treated with azoxystrobin, pyraclostrobin, fluxapyroxad/pyraclostrobin, and the cuprous oxide + chlorothalonil had significantly lower SAUDPC ranks than the untreated inoculated control (Table 4).

Significant differences among fungicide treatments in total yield were found for experiments 2011-A and 2012-C $(P<0.0001)$ but not for experiment $2011-\mathrm{B}$. $(P=0.604)$. In the 2012 trial $\mathrm{C}$, the majority of the total yield reported was nonmarketable (trimmings, Fig. 4). In the 2011 experiments, azoxystrobin and pyraclostrobin had the greatest marketable yield, and chlorothalonil and difenoconazole had intermediate marketable yield compared with the strobilurin treatments. Fungicide products such as copper hydroxide and fluopyram/pyrimethanil had marketable yields similar to the untreated inoculated control (Fig. 4).

\section{Discussion}

Celery anthracnose was present in all of the main celery production counties in Michigan, not only in 2010 (when the disease was first reported in the United States) but also in 2011 and 2012. It is unclear whether the disease will become a yearly challenge for celery

Table 3. Test statistics for the effects of fungicide treatments on final incidence and severity of celery anthracnose in 'Green Bay' celery inoculated with a mixture of isolates of Colletotrichum acutatum sensu lato in the field

\begin{tabular}{|c|c|c|c|c|c|c|c|c|c|c|c|}
\hline \multirow[b]{3}{*}{ Trial } & & & & \multicolumn{7}{|c|}{ Mean SAUDPC $\operatorname{rank}^{x}$} & \multirow[b]{3}{*}{$N^{\mathbf{z}}$} \\
\hline & \multicolumn{3}{|c|}{ Final incidence $(\%)$} & \multicolumn{3}{|c|}{ Wald-type statistic } & \multicolumn{4}{|c|}{ Analysis of variance-type statistic } & \\
\hline & df & $\boldsymbol{F}$ & $P$ value & df & $x^{2}$ & $P$ value & $\mathbf{d f}_{N}$ & $\mathbf{d f}_{D}$ & $\boldsymbol{F}$ & $P$ value & \\
\hline $2011-\mathrm{A}$ & 10 & 4.89 & $<0.0001$ & 10 & 306.38 & $<0.0001$ & 4.8 & 15 & 12.72 & $<0.0001$ & $\overline{1,015}$ \\
\hline 2011-B & 10 & 6.72 & $<0.0001$ & 10 & 773.83 & $<0.0001$ & 5.25 & 16.5 & 19.17 & $<0.0001$ & 971 \\
\hline 2012-C & 13 & 93.03 & $<0.0001$ & 13 & 1598.69 & $<0.0001$ & 7.85 & 24.6 & 6.58 & $<0.0001$ & 857 \\
\hline
\end{tabular}

${ }^{\mathrm{x}}$ Disease severity area under the disease curve (SAUDPC) mean ranks calculated based on an ordinal scale of severity, where $0=$ no symptoms, $1=>1$ to $10 \%$, $2=>10$ to $25 \%, 3=>25$ to $50 \%, 4=>50$ to $75 \%$, and $5=>75$ to $100 \%$ of plant area showing leaf curl and petiole anthracnose symptoms. Mean SAUDPC ranks were determined across replications.

y Symbols: $\mathrm{df}_{N}=$ numerator degrees of freedom and $\mathrm{df}_{D}=$ denominator degrees of freedom.

${ }^{\mathrm{z}} N=$ total number experimental units; each fungicide treatment was replicated in four blocks, and subsamples (celery plants) within the center of the plot were rated weekly from 5 to 53 days after inoculation.

Table 4. Effect of fungicide treatments on final incidence (\%) and severity of celery anthracnose (area under the disease curve [SAUDPC] mean rank) in 'Green Bay' celery inoculated with a mixture of isolates of Colletotrichum acutatum s.l. in the field ${ }^{\mathrm{x}}$

\begin{tabular}{|c|c|c|c|c|c|c|}
\hline \multirow[b]{2}{*}{ Fungicide (a.i.) treatment ${ }^{\mathrm{z}}$} & \multicolumn{3}{|c|}{ Final incidence $(\%)$} & \multicolumn{3}{|c|}{ Mean SAUDPC $\operatorname{rank}^{y}$} \\
\hline & 2011-A & 2011-B & 2012-C & 2011-A & 2011-B & 2012-C \\
\hline Untreated inoculated & $100.0 \mathrm{a}$ & $95.8 \mathrm{a}$ & $100.0 \mathrm{a}$ & $747.2 \mathrm{a}$ & $731.5 \mathrm{a}$ & $508.4 \mathrm{ab}$ \\
\hline Untreated noninoculated & nt & nt & $17.1 \mathrm{c}$ & nt & nt & $34.4 \mathrm{~g}$ \\
\hline Azoxystrobin & $50.5 \mathrm{c}$ & $65.5 \mathrm{c}-\mathrm{e}$ & $98.3 \mathrm{a}$ & $246.9 \mathrm{e}$ & $341.3 \mathrm{c}$ & $362.0 \mathrm{cdef}$ \\
\hline Boscalid & nt & nt & $100.0 \mathrm{a}$ & nt & nt & $604.1 \mathrm{a}$ \\
\hline Chlorothalonil & $72.9 \mathrm{bc}$ & $67.5 \mathrm{~b}-\mathrm{e}$ & $100.0 \mathrm{a}$ & $471.0 \mathrm{cbd}$ & $321.0 \mathrm{~cd}$ & 503.2 abcdef \\
\hline Copper hydroxide & $98.2 \mathrm{a}$ & $88.5 \mathrm{a}-\mathrm{c}$ & $100.0 \mathrm{a}$ & $617.5 \mathrm{~b}$ & $699.7 \mathrm{a}$ & $532.0 \mathrm{a}$ \\
\hline Cuprous oxide + chlorothalonil & $80.2 \mathrm{ab}$ & $69.5 \mathrm{~b}-\mathrm{d}$ & $98.4 \mathrm{a}$ & 429.6 cde & $306.7 \mathrm{c}$ & $331.4 \mathrm{f}$ \\
\hline Difenoconazole & 98.9 a & 75.0 a-d & $100.0 \mathrm{a}$ & $503.5 \mathrm{cb}$ & $459.5 \mathrm{bc}$ & $466.2 \mathrm{bcd}$ \\
\hline Fluopyram/pyrimethanil & $99.0 \mathrm{a}$ & $96.5 \mathrm{a}$ & $100.0 \mathrm{a}$ & $755.6 \mathrm{a}$ & $721.2 \mathrm{a}$ & $489.1 \mathrm{abcd}$ \\
\hline Fluxapyroxad/pyraclostrobin & nt & nt & $100.0 \mathrm{a}$ & nt & nt & 354.0 def \\
\hline Mancozeb & $51.9 \mathrm{c}$ & $44.8 \mathrm{e}$ & $100.0 \mathrm{a}$ & $241.9 \mathrm{e}$ & $209.0 \mathrm{~d}$ & 485.2 abcdf \\
\hline Propiconazole & $95.7 \mathrm{ab}$ & $91.5 \mathrm{ab}$ & $100.0 \mathrm{a}$ & $568.6 \mathrm{cb}$ & $548.9 \mathrm{~b}$ & $529.1 \mathrm{abc}$ \\
\hline Pyraclostrobin & $51.6 \mathrm{c}$ & $52.3 \mathrm{de}$ & $93.6 \mathrm{~b}$ & $290.0 \mathrm{ed}$ & $273.3 \mathrm{~cd}$ & 341.7 ef \\
\hline Pyrimethanil & $99.0 \mathrm{a}$ & $99.0 \mathrm{a}$ & $98.4 \mathrm{a}$ & $675.8 \mathrm{ab}$ & $725.6 \mathrm{a}$ & 474.1 abcdef \\
\hline
\end{tabular}

x Field trial year identification: 2011 trial A, 2011 trial B, and 2012 trial C. Values with common letters are not significantly different (least square difference $P=0.05)$ within a year and column; $\mathrm{nt}=$ not tested.

y Disease severity area under the disease curve (SAUDPC) mean ranks calculated based on an ordinal scale, where severity was visually assessed using a 0 -to-5 scale, as follows; $0=$ no symptoms, $1=>1$ to $10 \%, 2=>10$ to $25 \%, 3=>25$ to $50 \%, 4=>50$ to $75 \%$, and $5=>75$ to $100 \%$ of plant area showing leaf curl and petiole anthracnose symptoms. Mean SAUDPC ranks were determined across replications.

z Fungicide treatments were applied at 7 - to 10 -day $(7 \pm 2$ days $)$ intervals. 
growers in Michigan. Reports from Australia have indicated that, although leaf curl in celery is sporadic, outbreaks resulted in 25 to $50 \%$ yield losses when they occurred (Heaton and Dullahide 1993). Thus, continued research on celery anthracnose beyond the present study will be necessary to achieve long-term control of this disease and ensure the sustainability of the celery industry in Michigan.

When sampling for celery anthracnose in this study, symptoms could be clearly distinguished from other celery diseases such as early, late, and bacterial blights. Previous studies had reported leaf cupping, petiole twisting, and long, elliptical lesions on petioles as typical symptoms of celery anthracnose (Rodríguez-Salamanca et al. 2012). In this study, in addition to the previously described brown-colored lesions that developed along the petioles, lesions that resembled cracks with brown edges and occasionally adventitious roots formed. Leaf curling and petiole twisting were observed on seedlings and older celery plants. The celery heart (younger tissue in the center of the plant) was discolored in affected plants and was often observed in plants with curled leaves and discolored margins.

The morphological characterization of isolates revealed that the conidial size of $C$. acutatum s.l. isolates from celery was within the values previously reported for the $C$. acutatum complex (Damm et al. 2012; Sutton 1980; Thaung 2008). In addition, molecular characterization of isolates by using a $C$. acutatum species-specific marker established that 109 isolates obtained from celery belonged to this complex. Genetic diversity analyses of isolates using ISSR markers determined that isolates had a low polymorphism rate, because most of the celery isolates had banding patterns with identical fragment size and band presence. Additional markers could provide further insight regarding the genetic diversity of the C. acutatum s.l. population recovered from symptomatic celery but the markers used in the present study revealed low genetic diversity and a clonal genetic structure. A single clonal genetic structure would be consistent with the introduction of $C$. acutatum s.l. isolates to celery greenhouses and fields via infected seed or transplants. Alternatively, C. acutatum s.l. may be associated with weed species present in celery fields or the greenhouse as asymptomatic quiescent infections. These could serve as a source of inoculum similar to the strawberry pathosystem (Freeman et al. 2001a; Peres et al. 2005; Sreenivasaprasad and Talhinhas 2005). Clonal population structure has also been reported in C. acutatum isolates infecting fruit and almond (AfanadorKafuri et al. 2003; Denoyes-Rothan et al. 2003; Freeman et al. 2000).

All (but one) of the C. acutatum s.l. isolates from celery, tomato, and blueberry in this study were pathogenic on celery seedlings. The pathogen was recovered from infected seedlings by performing isolations from lesions in the petioles; nonetheless, some isolates were recovered from asymptomatic seedlings. When pathogenic, this genus of fungi can establish biotrophic infections that can result in periods of latent or quiescent infections (King et al. 1997; Peres et al. 2005). This initial biotrophic interaction with the host is consistent with asymptomatic seedlings observed on the first and second disease rating dates of pathogenicity and virulence assays that showed symptoms later in the experiment. This is a significant observation for disease management because asymptomatic (and undetected symptomatic) transplants can go misdiagnosed, which will delay disease control efforts. Asymptomatic transplants can also become a source of inoculum for celery fields due to short-distance dispersal of the pathogen once lesions become active, or due to movement of infected plant material that appears healthy.

Differences in virulence among C. acutatum s.l. isolates from celery were observed. The high variability in LAUDPC could be explained by differences in virulence determinants among isolates, resulting in specific isolate-host interactions. The reaction of celery cultivars to different $C$. acutatum s.l. isolates remains to be studied in detail, because regional cultivar specialization has been reported in other Colletotrichum spp. (Balardin et al. 1997; Mahuku and Riascos 2004). Several studies have characterized Colletotrichum spp. isolate virulence using a series of cultivars or differentials with diverse genetic backgrounds (Balardin et al. 1997; Denoyes and Baudry 1995; Falconi et al. 2013; Sharma et al. 2005), a logical next step for investigating virulence of $C$. acutatum s.l. isolated from celery.

Epidemiological studies determined that celery anthracnose was influenced by temperature and leaf wetness duration similar to what has been reported in other Colletotrichum spp. infecting various hosts (Dieguez-Uribeondo et al. 2011; Moral et al. 2012; Wilson et al. 1990). Symptoms were especially severe at warmer temperatures $\left(\geq 25^{\circ} \mathrm{C}\right)$ or at longer leaf wetness duration periods $(\geq 48 \mathrm{~h})$. Regardless, C. acutatum s.l. infected celery and caused disease at all

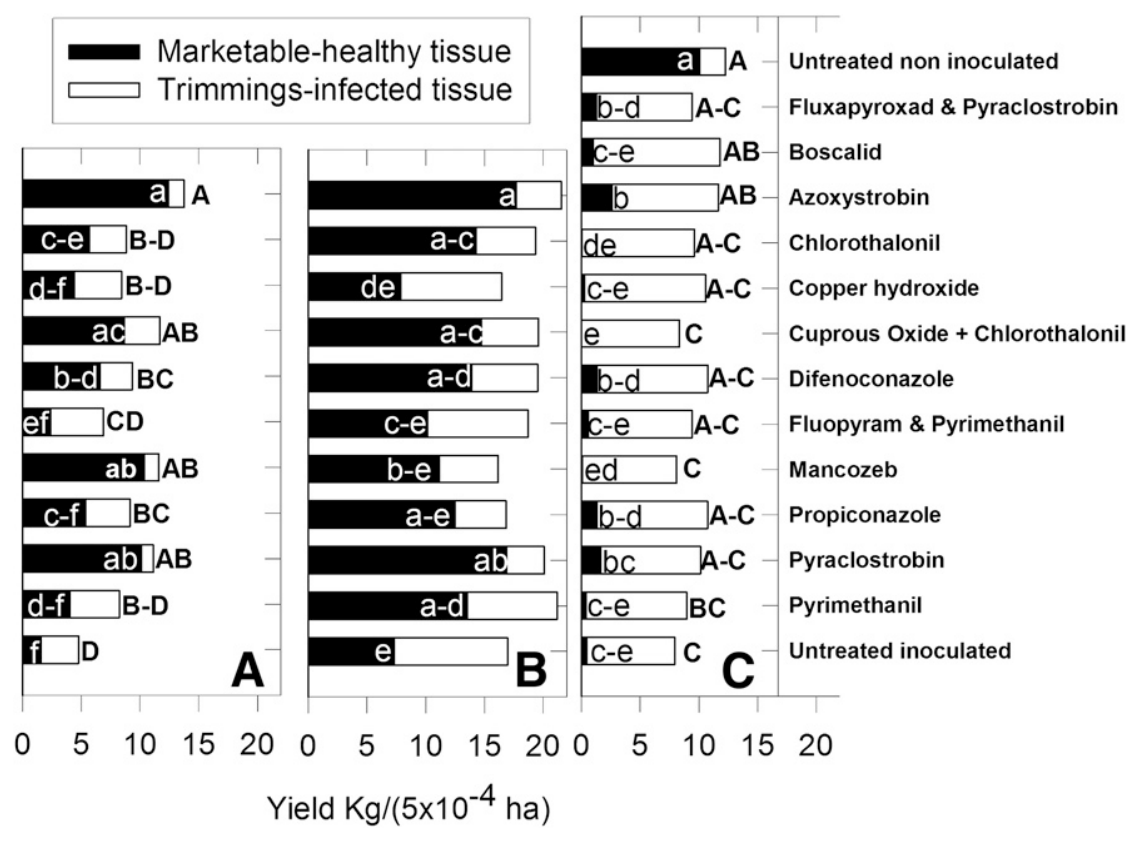

Fig. 4. Yield differences among fungicide treatments in "Green Bay" celery inoculated with Colletotrichum acutatum sensu lato mixture of isolates. Field trial year identification: A, 2011 trial A; B, 2011 trial B; and C, 2012 trial C. Symbols: $(+)=$ treatments were tank mixed prior to application and $(/)=$ premix product. White bars are infected tissue trimmed from the plant at time of harvest. Black bars represent the marketable yield. Uppercase letters illustrate significant differences among total yield $(P=0.05)$ and lowercase letters represent significant differences. 
temperatures and leaf wetness durations tested. Celery production in Michigan, and in most U.S. celery-growing regions, starts with transplants in the greenhouse at temperatures ranging between 15 and $25^{\circ} \mathrm{C}$ (night and day, respectively), conditions which could promote infections early in the celery-growing cycle. In addition, celery seedlings in the greenhouses are watered daily, which creates periods of leaf wetness and RH conducive to infection and symptom development. Celery seedlings could become infected in the greenhouse from inoculum originating from contaminated reused plug trays, asymptomatic weeds, or infected seed, similar to other Colletotrichum spp. (Freeman et al. 2001a; Peres et al. 2005). Data from this study indicate that the progression of symptoms would be slow as long as temperatures ranged between 15 and $20^{\circ} \mathrm{C}$. Symptom development could peak in late spring in the greenhouses or in the summer months in the field, when temperatures become warmer $(\geq 25$ to $\left.30^{\circ} \mathrm{C}\right)$.

Periods of leaf wetness are created in the field by rainfall or by the overhead irrigation implemented by most growers in Michigan. Irrigation is required for this shallow-root, cool-season biennial; however, limiting irrigation duration to minimize periods of leaf wetness and C. acutatum s.l. inoculum splash could help limit the severity of celery anthracnose. Drip irrigation can meet celery water requirements (Breschini and Hartz 2002) while minimizing splash dispersal of $C$. acutatum s.l.; however, its economic feasibility in Michigan needs to be evaluated. Drip irrigation in California celery fields has increased since the late 1990s (Breschini and Hartz 2002; Koike et al. 1996).

In field studies to evaluate fungicide efficacy for disease control on artificially inoculated plants, anthracnose developed on almost $100 \%$ of plants in the untreated inoculated plots. Strobilurin fungicides (azoxystrobin and pyraclostrobin) and mancozeb reduced celery anthracnose incidence by 48 and $30 \%$ in the 2011 trials A and B, respectively. Chlorothalonil alone or tank mixed with copper reduced incidence by 20 to $27 \%$ in 2011 trials. In 2012, disease incidence across inoculated and treated plots was $>80 \%$ by the second rating date and, at the final rating date, only pyraclostrobin was significantly different from the other fungicide treatments. Increased disease severity observed in the 2012 fungicide plots may be a result of the increased irrigation that was required to sustain the crop due to drier than normal weather in June and early July. Frequent irrigation favors disease development and increases the potential for a reduction in fungicide residue wash off. Also, temperatures increased $\left(21 \pm 1\right.$ to $\left.35 \pm 2^{\circ} \mathrm{C}\right)$ prior to the curative spray ( 5 July) compared with temperatures $\left(15 \pm 4\right.$ to $\left.31 \pm 2^{\circ} \mathrm{C}\right)$ the week of the preventive spray (28 June) and inoculation (30 June). Increased precipitation and temperatures from mid-July through early August favored the polycyclic phase of the pathogen's disease cycle. Symptoms developed rapidly on treated inoculated plots and likely increased pathogen dispersal, resulting in symptomatic plants on the noninoculated control plants.

In trial 2011-A, heavy rainfall events occurred between applications 4 and 5 and anthracnose incidence increased rapidly because inoculum present in the plots was likely splash dispersed, and extended periods of leaf wetness conducive to infection and symptom development were present. Efficacious fungicides need to be applied to protect new and healthy celery tissue prior to forecasted rain events that promote C. acutatum conidial splashing.

Across all experiments, plots treated with azoxystrobin, cuprous oxide +chlorothalonil, or pyraclostrobin had reduced disease severity (SAUDPC) compared with the untreated inoculated control. Under the severe celery anthracnose pressure in trial 2011-A (Table 4), the fungicides azoxystrobin, pyraclotrobin, chlorothalonil alone or mixed with cuprous oxide, and mancozeb limited anthracnose severity progression, compared with the untreated noninoculated control. Under moderate celery anthracnose severity (trial 2011-B; Table 4), chlorothalonil alone or tank mixed with copper was not significantly different than strobilurins in limiting celery anthracnose severity.

Celery is grown for its edible petioles, and the presence of blemishes, bruises, or disease lesions renders the petioles unmarketable (Bounds and Hausbeck 2007; Bounds and Hausbeck 2008). In field experiments, untreated inoculated plots resulted in 68,57 , and $94 \%$ symptomatic tissue at harvest time. Even though severe celery anthracnose affected total and marketable yields, efficacious fungicides that limited disease severity and incidence, such as strobilurins, resulted in higher total and marketable yields compared with the untreated control. Chlorothalonil, fluopyram/pyrimethanil, and pyrimethanil resulted in total yield similar to that of the untreated inoculated. However, chlorothalonil decreased celery anthracnose incidence and severity, protecting marketable yield, which was significantly different from the untreated inoculated control in the 2011-A trial.

Mancozeb suppressed anthracnose incidence and severity second to the strobilurins; nonetheless, mancozeb did not prevent yield loss as the strobilurin fungicides did and is not currently registered for use on celery in the United States. Protectant fungicides play a key role in avoiding fungicide resistance to site-specific fungicides reported in several pathosystems (Avila-Adame et al. 2003). Celery growers should tank mix strobilurins with protectant fungicides to delay C. acutatum s.l. resistance to strobilurins (Brent and Hollomon 2007; Matheron and Porchas 2013; Van den Bosch et al. 2014) while minimizing yield losses.

Green Bay celery was used across experiments in this study but at least five different celery cultivars are grown in Michigan ('Sabrosa', 'Sweet Sensation', 'CR1', Green Bay, and 'Duchess'), and different cultivars are grown in California, Florida, and minor celery-producing states in the United States. Identifying celery cultivars resistant to anthracnose or with a limited number of lesions in the petioles will be crucial to minimize diseased tissue trimmings and the additional labor involved in trimming symptomatic petioles, and reduce fungicide applications and the cost associated with both of these management options.

\section{Acknowledgments}

We thank all the members of the Hausbeck lab for their valuable help; A. Cortright, T. Guo, and J. Harig for technical assistance; and J. Fry and L. V. Madden for guidance with nonparametric data analysis. This work was supported by MSU GREEEN GR11-030 and GR11-020 and Michigan Celery Inc. L. Quesada-Ocampo was supported by NIFA/USDA project NC02418.

\section{Literature Cited}

Adaskaveg, J. E., and Forster, H. 2000. Occurrence and management of anthracnose epidemics caused by Colletotrichum species on tree fruit crops in California. Pages 317-336 in: Colletotrichum, Host Specificity, Pathology, and Host-Pathogen Interaction. D. Prusky, S. Freeman, and M. B. Dickman, eds. American Phytopathological Society, St. Paul, MN.

Afanador-Kafuri, L., Minz, D., Maymon, M., and Freeman, S. 2003. Characterization of Colletotrichum isolates from tamarillo, passiflora, and mango in Colombia and identification of a unique species from the genus. Phytopathology 93:579-587.

Anonymous. 2012. Web Soil Survey. Soil Survey Staff, Natural Resources Conservation Service, United States Department of Agriculture. Online publication. http://websoilsurvey.nrcs.usda.gov/

Anonymous. 2013. Vegetables 2013 Summary January 2014. USDA National Agricultural Statistic Service. Online publication. http://www.nass.usda. gov/Publications/Ag_Statistics/2013/

Avila-Adame, C., Olaya, G., and Köller, W. 2003. Characterization of Colletotrichum graminicola isolates resistant to strobilurin-related QoI fungicides. Plant Dis. 87: 1426-1432.

Balardin, R. S., Jarosz, A. M., and Kelly, J. D. 1997. Virulence and molecular diversity in Colletotrichum lindemuthianum from South, Central, and North America. Phytopathology 87:1184-1191.

Bounds, R. S., and Hausbeck, M. K. 2007. Comparing disease predictors and fungicide programs for late blight management in celery. Plant Dis. 91: 532-538.

Bounds, R. S., and Hausbeck, M. K. 2008. Evaluation of disease thresholds and predictors for managing late blight in celery. Plant Dis. 92:438-444.

Brent, K. J., and Hollomon, D. W. 2007. Fungicide Resistance in Crop Pathogens: How Can It Be Managed? FRAC Monogr. No. 1, 2nd ed. FRAC, Brussels.

Breschini, S. J., and Hartz, T. K. 2002. Drip irrigation management affects celery yield and quality. HortScience 37:894-897.

Chapin, L. J., Wang, Y., Lutton, E., and McSpadden Gardener, B. B. 2006. Distribution and fungicide sensitivity of fungal pathogens causing anthracnoselike lesions on tomatoes grown in Ohio. Plant Dis. 90:397-403.

Damm, U., Cannon, P. F., Woudenberg, J. H. C., and Crous, P. W. 2012. The Colletotrichum acutatum species complex. Stud. Mycol. 73:37-113.

Denoyes, B., and Baudry, A. 1995. Species identification and pathogenicity study of French Colletotrichum strains isolated from strawberry using morphological and cultural characteristics. Phytopathology 85:53-57. 
Denoyes-Rothan, B., Guerin, G., Delye, C., Smith, B., Minz, D., Maymon, M., and Freeman, S. 2003. Genetic diversity and pathogenic variability among isolates of Colletotrichum species from strawberry. Phytopathology 93:219-228.

Dhingra, O. D., and Sinclair, J. B. 1985. Basic Plant Pathology Methods. CRC Press Inc., Boca Raton, FL.

Dieguez-Uribeondo, J., Forster, H., and Adaskaveg, J. E. 2011. Effect of wetness duration and temperature on the development of anthracnose on selected almond tissues and comparison of cultivar susceptibility. Phytopathology 101:1013-1020.

Falconi, C. E., Visser, R. G. F., and van Heusden, A. W. 2013. Phenotypic, molecular, and pathological characterization of Colletotrichum acutatum associated with Andean lupine and tamarillo in the Ecuadorian Andes. Plant Dis. 97:819-827.

Freeman, S. 2008. Management, survival strategies, and host range of Colletotrichum acutatum on strawberry. HortScience 23:66-68.

Freeman, S., Nizani, Y., Dotan, S., Even, S., and Sando, T. 1997. Control of Colletotrichum acutatum in strawberry under laboratory, greenhouse, and field conditions. Plant Dis. 81:749-752.

Freeman, S., Minz, D., Jurkevitch, E., Maymon, M., and Shabi, E. 2000. Molecular analyses of Colletotrichum species from almond and other fruits. Phytopathology 90:608-614.

Freeman, S., Horowitz, S., and Sharon, A. 2001a. Pathogenic and nonpathogenic lifestyles in Colletotrichum acutatum from strawberry and other plants. Phytopathology 91:986-992.

Freeman, S., Minz, D., Maymon, M., and Zveibil, A. 2001b. Genetic diversity within Colletotrichum acutatum sensu Simmonds. Phytopathology 91:586-592.

Guerber, J. C., Liu, B., Correll, J. C., and Johnston, P. R. 2003. Characterization of diversity in Colletotrichum acutatum sensu lato by sequence analysis of two gene introns, mtDNA and intron RFLPs, and mating compatibility. Mycologia 95: 872-895.

Heaton, J. B., and Dullahide, S. R. 1993. Control of celery leaf curl disease caused by Colletotrichum acutatum. Australas. Plant Pathol. 22:152-155.

Jeffries, P., Dodd, J. C., Jeger, M. J., and Plumbley, R. A. 1990. The biology and control of Colletotrichum species on tropical fruit crops. Plant Pathol. 39:343-366.

Johnston, P. R., and Jones, D. 1997. Relationships among Colletotrichum isolates from fruit-rots assessed using rDNA sequences. Mycologia 89:420-430.

King, W. T., Madden, L. V., Ellis, M. A., and Wilson, L. L. 1997. Effects of temperature on sporulation and latent period of Colletotrichum spp. infecting strawberry fruit. Plant Dis. 81:77-84.

Koike, S. T., Schulbach, K. F. and Chaney, W. E. 1996. Celery production in California. Calif. Coop. Ext. Bul. 7220. University of California, Oakland, CA, http://anrcatalog.ucanr.edu/pdf/7220.pdf

Lardner, R., Johnston, P. R., Plummer, K. M., and Pearson, M. N. 1999. Morphological and molecular analysis of Colletotrichum acutatum sensu lato. Mycol. Res. 103:275-285.

Leandro, L. F. S., Gleason, M. L., Nutter, F. W., Wegulo, S. N., and Dixon, P. M. 2003. Influence of temperature and wetness duration on conidia and appressoria of Colletotrichum acutatum on symptomless strawberry leaves. Phytopathology 93: 513-520.

MacKenzie, S. J., and Peres, N. A. 2012. Use of leaf wetness and temperature to time fungicide applications to control anthracnose fruit rot of strawberry in Florida. Plant Dis. 96:522-528.

Madden, L. V., and Boudreau, M. A. 1997. Effect of strawberry density on the spread of anthracnose caused by Colletotrichum acutatum. Phytopathology 87:828-838.

Madden, L. V., Wilson, L. L., and Ellis, M. A. 1993. Field spread of anthracnose fruit rot of strawberry in relation to ground cover and ambient weather conditions. Plant Dis. 77:861-866.
Mahuku, G. S., and Riascos, J. J. 2004. Virulence and molecular diversity within Colletotrichum lindemuthianum isolates from Andean and Mesoamerican bean varieties and regions. Eur. J. Plant Pathol. 110:253-263.

Maniatis, T., Fritsch, E. F., and Sambrook, J. 1982. Molecular Cloning: A Laboratory Manual. Cold Spring Harbor Laboratory Press, Cold Spring Harbor, NY.

Matheron, M. E., and Porchas, M. 2013. Efficacy of fungicides and rotational programs for management of powdery mildew on cantaloupe. Plant Dis. 97: 196-200.

Mills, P. R., Sreenivasaprasad, S., and Brown, A. E. 1992. Detection and differentiation of Colletotrichum gloeosporioides isolates using PCR. FEMS Microbiol. Lett. 98:137-143.

Mishra, P. K., Fox, R. T. V., and Culham, A. 2003. Inter-simple sequence repeat and aggressiveness analyses revealed high genetic diversity, recombination and long-range dispersal in Fusarium culmorum. Ann. Appl. Biol. 143:291-301.

Moral, J., Jurado-Bello, J., Sanchez, M. I., de Oliveira, R., and Trapero, A. 2012 Effect of temperature, wetness duration, and planting density on olive anthracnose caused by Colletotrichum spp. Phytopathology 102:974-981.

Ntahimpera, N., Madden, L. V., and Wilson, L. L. 1997. Effect of rain distribution alteration on splash dispersal of Colletotrichum acutatum. Phytopathology 87: 649-655.

Peres, N. A., Timmer, L. W., Adaskaveg, J. E., and Correll, J. C. 2005. Lifestyles of Colletotrichum acutatum. Plant Dis. 89:784-796.

Rampersad, S. N. 2013. Genetic structure of Colletotrichum gloeosporioides sensu lato isolates infecting papaya inferred by multilocus ISSR markers. Phytopathology 103:182-189.

Rodríguez-Salamanca, L. M., Enzenbacher, T. B., Byrne, J. M., Feng, C., Correll, J. C., and Hausbeck, M. K. 2012. First report of Colletotrichum acutatum causing leaf curling and petiole anthracnose on celery (Apium graveolens) in Michigan. Plant Dis. 96:1383.

Shah, D. A., and Madden, L. V. 2004. Nonparametric analysis of ordinal data in designed factorial experiments. Phytopathology 94:33-43.

Sharma, P. N., Kaur, M., Sharma, O. P., Sharma, P., and Pathania, A. 2005. Morphological, pathological and molecular variability in Colletotrichum capsici, the cause of fruit rot of chillies in the subtropical region of northwestern India. J. Phytopathol. 153:232-237.

Silva-Rojas, H. V., and Ávila-Quezada, G. D. 2011. Phylogenetic and morphological identification of Colletotrichum boninense: A novel causal agent of anthracnose in avocado. Plant Pathol. 60:899-908.

Sreenivasaprasad, S., and Talhinhas, P. 2005. Genotypic and phenotypic diversity in Colletotrichum acutatum, a cosmopolitan pathogen causing anthracnose on a wide range of hosts. Mol. Plant Pathol. 6:361-378.

Sutton, B. C. 1980. The Coelomycetes: Fungi Imperfecti with Pycnidia Acervuli and Stromata. CABI international, New York.

Thaung, M. 2008. Coelomycete systematics with special reference to Colletotrichum. Mycoscience 49:345-350.

Van den Bosch, F., Paveley, N., Van den Berg, F., Hobbelen, P., and Oliver, R. 2014. Mixtures as a fungicide resistance management tactic. Phytopathology 104:1264-1273

Whitelaw-Weckert, M. A., Curtin, S. J., Huang, R., Steel, C. C., Blanchard, C. L., and Roffey, P. E. 2007. Phylogenetic relationships and pathogenicity of Colletotrichum acutatum isolates from grape in subtropical Australia. Plant Pathol. 56:448-463.

Wilson, L. L., Madden, L. V., and Ellis, M. A. 1990. Influence of temperature and wetness duration on infection of immature strawberry fruit by Colletotrichum acutatum. Phytopathology 80:111-116. 